Article

\title{
Solvent-Free Desulfurization System to Produce Low-Sulfur Diesel Using Hybrid Monovacant Keggin-Type Catalyst
}

\author{
Fátima Mirante, Baltazar de Castro, Carlos M. Granadeiro ${ }^{\mathbb{D}}$ and Salete S. Balula *(D) \\ LAQV-REQUIMTE, Departamento de Química e Bioquímica, Faculdade de Ciências, Universidade do Porto, \\ 4169-007 Porto, Portugal; fatima.mirante@fc.up.pt (F.M.); bcastro@fc.up.pt (B.d.C.); \\ cgranadeiro@fc.up.pt (C.M.G.) \\ * Correspondence: sbalula@fc.up.pt; Tel.: +351-220-402-576; Fax: +351-220-402-659
}

Academic Editor: Alexander O. Terent'ev Received: 19 September 2020; Accepted: 26 October 2020; Published: 27 October 2020

Abstract: Two quaternary ammonium catalysts based on the monovacant polyoxotungstate $\left(\left[\mathrm{PW}_{11} \mathrm{O}_{39}\right]^{7-}\right.$, abbreviated as $\left.\mathrm{PW}_{11}\right)$ were prepared and characterized. The desulfurization performances of the $\mathrm{PW}_{11}$-based hybrids (of tetrabutylammonium and trimethyloctadecylammonium, abbreviated as TBA[PW $\left.\mathrm{PW}_{11}\right]$ and $\mathrm{ODA}\left[\mathrm{PW}_{11}\right]$, respectively), the corresponding potassium salt $\left(\mathrm{K}_{7} \mathrm{PW}_{11} \mathrm{O}_{39}\right.$, abbreviated as $\left.\mathrm{KPW}_{11}\right)$ and the peroxo-compound (TBA-PO $\mathrm{P}_{4}\left[\mathrm{WO}\left(\mathrm{O}_{2}\right)_{2}\right]$, abbreviated as $\mathrm{TBA}\left[\mathrm{PW}_{4}\right]$ ) were compared as catalysts for the oxidative desulfurization of a multicomponent model diesel (2000 ppm S). The oxidative desulfurization studies (ODS) were performed using solvent-free systems and aqueous $\mathrm{H}_{2} \mathrm{O}_{2}$ as oxidant. The nature of the cation in the $\mathrm{PW}_{11}$ catalyst showed to have an important influence on the catalytic performance. In fact, the $\mathrm{PW}_{11}$-hybrid catalysts showed higher catalytic efficiency than the peroxo-compound TBA[PW $\left.\mathrm{PW}_{4}\right]$, known as Venturello compound. $\mathrm{TBA}\left[\mathrm{PW}_{11}\right]$ revealed a remarkable desulfurization performance with $96.5 \%$ of sulfur compounds removed in the first $130 \mathrm{~min}$. The reusability and stability of the catalyst were also investigated for ten consecutive ODS cycles without loss of activity. A treated clean diesel could be recovered without sulfur compounds by performing a final liquid/liquid extraction diesel/EtOH: $\mathrm{H}_{2} \mathrm{O}$ mixture (1:1) after the catalytic oxidative step.

Keywords: polyoxometalate; pseudo-monophasic desulfurization; fuel; sulfur oxidation; hydrogen peroxide

\section{Introduction}

The deep desulfurization of transportation fuels has received worldwide attention as a result of the increasingly rigid regulations concerning sulfur content in fuels. The traditional hydrodesulfurization (HDS) technology requires severe operational conditions and is less efficient in removing the aromatic sulfur compounds (dibenzothiophene and derivatives) present in fuels [1,2]. Different complementary desulfurization processes have been studied based on extraction, adsorption, oxidation or even biological methods [3-5]. The combination of extraction and oxidation steps, in the so-called extractive and catalytic oxidative desulfurization (ECODS) method, allows a highly efficient removal of refractory sulfur compounds under mild and eco-sustainable conditions [6-11]. Recently, there has been an increasing effort in developing solvent-free desulfurization systems [3]. These systems are intended to still efficiently remove organosulfur compounds from fuels with the environmental and economic advantages of avoiding the use of the traditional volatile organic solvents [12,13]. Jia and co-workers have proposed a solvent-free ODS system using a $\mathrm{MoO}_{3} / \gamma-\mathrm{Al}_{2} \mathrm{O}_{3}$ catalyst and $\mathrm{H}_{2} \mathrm{O}_{2}$ as oxidant [13]. Complete oxidation of dibenzothiophene (DBT) and 4,6-dimethyldibenzothiophene (4,6-DMDBT) could be reached after just $15 \mathrm{~min}$ of reaction. Regeneration of the catalyst was achieved by washing with methanol for reuse in consecutive cycles, although some loss of activity could be observed. 
Polyoxometalates (POMs) are versatile compounds with peculiar physicochemical properties that enable their application in diverse fields such as magnetism, luminescence, medicine and catalysis [14]. Over the years, POMs and Keggin-type structures, in particular, have become increasingly used in acid and oxidative catalysis due to their remarkable activity and stability [15]. Our research group has been investigating novel POM-based eco-sustainable desulfurization systems for the production of sulfur-free fuels [16-22]. Recently, we have also been developing solvent-free systems able to match the desulfurization performance of biphasic systems while allowing the use of more sustainable extraction solvents for the final removal of oxidized products (e.g., water) [23-25]. The preparation of organic-POM hybrids by introduction of different organic cations (ionic liquids, surfactants and polymers) has proved to be a simple methodology for the heterogenization of active homogenous POMs while maintaining their catalytic performance [26-28]. Some examples can be found in the literature dealing with the application of these organic-POM hybrids in oxidative desulfurization of model and real fuels [29-39]. Campos-Martin et al. have recently reported an hybrid POM composed by a vanadium-substituted Dawson anion $\left(\left[\mathrm{P}_{2} \mathrm{~W}_{13} \mathrm{~V}_{5} \mathrm{O}_{62}\right]^{11-}\right)$ and cetrimonium cations [38]. The hybrid was evaluated as a catalyst in the ECODS process of a model fuel using $\mathrm{H}_{2} \mathrm{O}_{2}$ as oxidant. The optimum experimental conditions allowed a sulfur removal of approximately $90 \%$ after 45 min and the system could be recycled for seven cycles.

In this work, we have evaluated two quaternary ammonium salts of the monovacant Keggin-type phosphotungstate $\left(\left[\mathrm{PW}_{11} \mathrm{O}_{39}\right]^{7-}\right)$ as heterogeneous catalysts in solvent-free ODS processes. The tetrabutylammonium (TBA) and octadecyldimethylammonium (ODA) hybrids, as well as the potassium $(\mathrm{K})$ compound, were tested as catalysts in the desulfurization of a multicomponent model diesel with a total sulfur concentration of 2000 ppm. The proposed ODS system avoids the use of harmful organic solvents by efficiently removing organosulfur compounds under sustainable solvent-free conditions using $\mathrm{H}_{2} \mathrm{O}_{2}$ as oxidant and mixture of 1:1 water/ethanol for the removal of oxidized products. The reusability and stability of the TBA[PW $\left[\mathrm{PW}_{11}\right]$ were investigated for ten consecutive ODS cycles.

\section{Results and Discussion}

\subsection{Desulfurization of Model Diesel}

The ODS studies were performed using a model diesel containing the most refractory sulfur compounds in real diesel (500 ppm or $0.0156 \mathrm{~mol} \mathrm{dm}^{-3}$ of each): 1-benzothiophene (1-BT), dibenzothiophene (DBT), 4-methyldibenzothiophene (4-MDBT) and 4,6-dimethyldibenzothiophene (4,6-DMDBT) in n-octane. The oxidation of these sulfur compounds was performed using $\mathrm{H}_{2} \mathrm{O}_{2}$ as oxidant at $70{ }^{\circ} \mathrm{C}$ and catalyzed by the different salts of the monovacant Keggin-type POM (TBA[PW $\left.{ }_{11}\right]$, ODA[PW $\left.\mathrm{PW}_{11}\right]$ and $\left.\mathrm{K}\left[\mathrm{PW}_{11}\right]\right)$, which behaved as heterogeneous catalysts. The catalytic oxidative reaction was carried out under solvent-free conditions, thus avoiding the use of a polar organic solvent. In this system, the oxidation occurs in the diesel phase. Besides, the final extraction of the oxidized products can be conducted with a choice of more sustainable and more cost-effective solvents. This is an important feature for the future industrial application. The organic-inorganic $\mathrm{PW}_{11}$ catalysts $\left(\mathrm{TBA}\left[\mathrm{PW}_{11}\right]\right.$ and ODA[PW 11$]$ ) exhibited superior desulfurization performances to the corresponding potassium compound $\left(\mathrm{K}\left[\mathrm{PW}_{11}\right]\right)$ which showed negligible catalytic activity (Figure 1$)$. This must be due to the affinity of the organic cation of the hybrid catalysts with the model diesel phase, increasing the interphase between model diesel/catalyst/oxidant. On the other hand, the potassium catalyst as inorganic catalyst presents probably an absent interaction with the model diesel. The TBA[PW 11$]$ hybrid achieved total sulfur conversion at $190 \mathrm{~min}$ of reaction while ODA[PW 11$]$, despite reaching a desulfurization of $83 \%$ after only $20 \mathrm{~min}$, was unable to reach total sulfur conversion even after $4 \mathrm{~h}$. These results indicate that the nature of the cation from the catalyst has an important influence in its catalytic performance under a solvent-free system. 


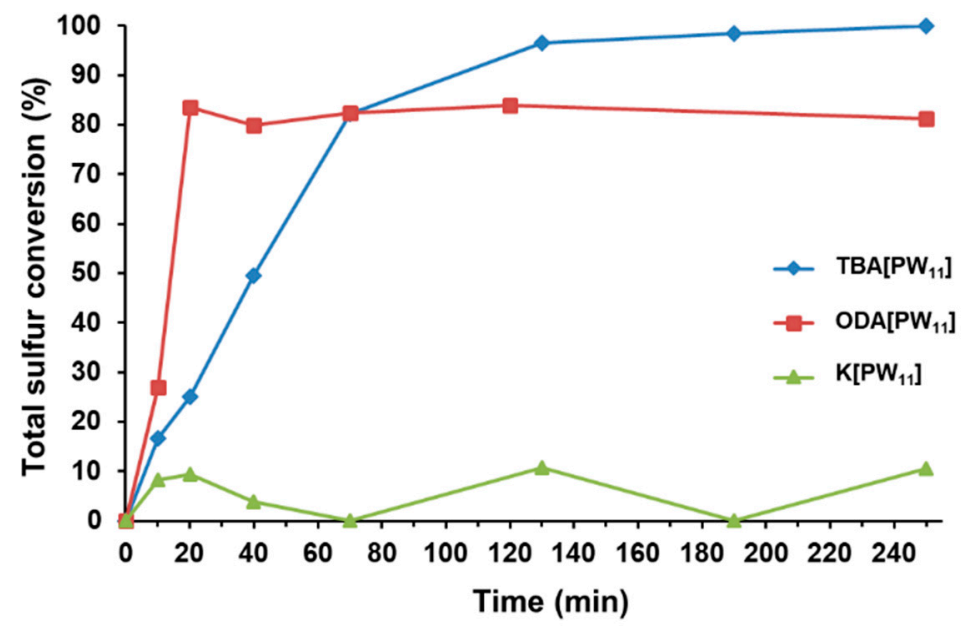

Figure 1. Kinetic profiles for the desulfurization of a model diesel under the solvent-free system, catalyzed by TBA[PW 11$]$, ODA $\left[\mathrm{PW}_{11}\right]$ or $\mathrm{K}\left[\mathrm{PW}_{11}\right]$, using $\mathrm{H}_{2} \mathrm{O}_{2}$ as oxidant $\left(\mathrm{H}_{2} \mathrm{O}_{2} / \mathrm{S}=3\right)$ at $70{ }^{\circ} \mathrm{C}$.

The solvent-free systems with the TBA[PW $\left.\mathrm{PW}_{11}\right]$ and ODA[PW $\left.\mathrm{PW}_{11}\right]$ catalysts were submitted to an optimization concerning the amount of oxidant. The same amount of catalyst as used in the ODS solvent-free process optimization $(3 \mu \mathrm{mol})$ was tested using a $\mathrm{H}_{2} \mathrm{O}_{2} / \mathrm{S}$ ratio of 3 and 8 , at $70^{\circ} \mathrm{C}$. The optimization results obtained for TBA[PW $\left.\mathrm{PW}_{11}\right]$ and $\mathrm{ODA}\left[\mathrm{PW}_{11}\right]$ are presented in Figure $2 \mathrm{~A}$ and Figure 2B, respectively. It was possible to observe that using the lowest amount of oxidant $\left(\mathrm{H}_{2} \mathrm{O}_{2} / \mathrm{S}=3\right)$ the total sulfur conversion could only be achieved with TBA[PW $\left.\mathrm{PW}_{11}\right]$. For the highest amount of oxidant $\left(\mathrm{H}_{2} \mathrm{O}_{2} / \mathrm{S}=8\right)$, total sulfur conversion was attained after $40 \mathrm{~min}$ with ODA[PW $\left.{ }_{11}\right]$ while the TBA[PW $\left.{ }_{11}\right]$ system kept a similar kinetic profile, with total sulfur conversion after $190 \mathrm{~min}$ of reaction. These results show that the nature of the cation and the length of the carbon chain in active center $P_{11}$ were revealed to have an important influence in the catalytic performance. The catalyst ODA[PW 11$]$, which has a longer carbon chain, proved to be more efficient in the sulfur oxidation of the model diesel than TBA[PW $\left.\mathrm{PW}_{11}\right]$, although it used a higher oxidant amount $\left(\mathrm{H}_{2} \mathrm{O}_{2} / \mathrm{S}=8\right)$. Xu et al. explained this phenomenon through the ability of surfactants with long carbon chains to attract the weakly polar sulfur compounds closer to the surface of POM-hybrids, hence promoting more frequent interactions between sulfur compounds and active species [40]. On the other hand, the higher amount of $\mathrm{H}_{2} \mathrm{O}_{2}$ oxidant needed to achieve complete desulfurization of model diesel catalyzed by ODA[PW $\left.\mathrm{PW}_{11}\right]$ is probably due to the difficult interaction of the polyanion from the catalyst $\left(\left[\mathrm{PW}_{11} \mathrm{O}_{39}\right]^{7-}\right)$ with the polar oxidant (aqueous $\left.\mathrm{H}_{2} \mathrm{O}_{2}\right)$, caused by its cationic long carbon chain $\left(\mathrm{ODA}^{+}\right)$. Similar behavior has also been previously reported by our group for biphasic desulfurization systems catalyzed by POM-hybrids and using acetonitrile or $[\mathrm{BMIM}]\left[\mathrm{PF}_{6}\right]$ as solvents [41-43]. Other results show a direct correlation between the carbon chain length of the quaternary ammonium cation in POM-hybrids and their catalytic activity in oxidative desulfurization $[34,40,44]$. More examples on the application of POM-based hybrids and quaternary ammonium cations in oxidative desulfurization can be found in the literature, with the majority using a biphasic catalytic system. However, more than $2 \mathrm{~h}$ are needed to achieve complete desulfurization [1,29-36]. Faster complete desulfurization was reported previously, but using a model diesel containing a single sulfur compound [31,33]. 

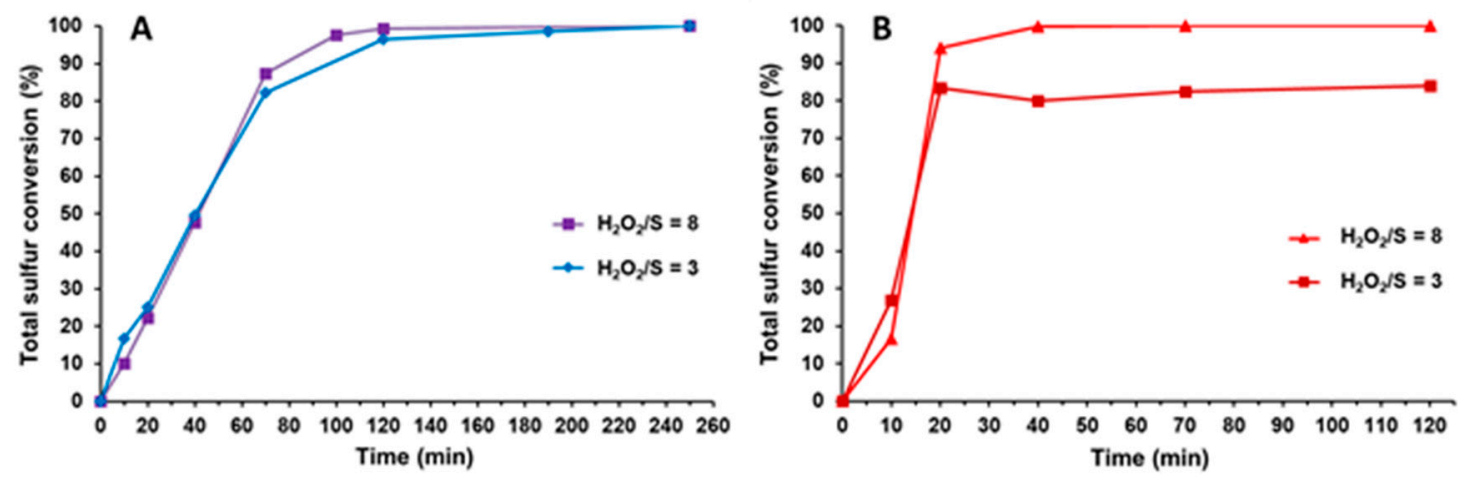

Figure 2. Total conversion data obtained for the oxidation of a multicomponent sulfur model diesel (2000 ppm S) at $70{ }^{\circ} \mathrm{C}$ using (A) TBA[PW $\left.{ }_{11}\right]$ and (B) ODA[PW $\left.{ }_{11}\right]$ catalysts $(3 \mu \mathrm{mol})$ and different amounts of $\mathrm{H}_{2} \mathrm{O}_{2}$ as oxidant.

To confirm that $\mathrm{PW}_{11}$ is the active center, a new catalyst was prepared with the same cation: the Venturello complex $\mathrm{TBA}_{4} \mathrm{H}_{3}\left[\mathrm{PW}_{4} \mathrm{O}_{24}\right]\left(\mathrm{TBA}\left[\mathrm{PW}_{4}\right]\right)$. This type of compound has been identified as an intermediate active species in a variety of oxidation reactions formed from the reaction of Keggin-type polyoxometalates with hydrogen peroxide [45-49]. The Venturello TBA[PW 4 ] was characterized by FTIR-ATR and ${ }^{31} \mathrm{P}$ NMR and the results were in agreement with the previously reported data by Julião et al. (Figures S1 and S2 in the ESI) [41,46]. However, under the same experimental catalytic conditions described above, the Venturello complex showed non activity in the solvent-free system, indicating that this is not an active intermediate.

\subsection{Reusability of the ODS System}

The reuse capacity of the TBA[PW $\left.{ }_{11}\right]$ hybrid catalyst was investigated in the solvent-free desulfurization system using $3 \mu \mathrm{mol}$ of catalyst and $\mathrm{H}_{2} \mathrm{O}_{2} / \mathrm{S}$ ratio of three for ten consecutive cycles. At the end of each cycle, the desulfurized model diesel was removed and an equal volume of fresh model diesel and oxidant were added to the ODS system, maintaining the same experimental conditions. The results show that the catalyst maintained its performance along ten consecutives ODS cycles reaching complete sulfur conversion after $3 \mathrm{~h}$ of reaction (Figure 3 ). These very promising results surpass the previously reported data for TBA[PW 11 biphasic systems with acetonitrile or [BMIM] $\left[\mathrm{PF}_{6}\right]$ since, in these systems, a decrease in the desulfurization efficiency could be detected during the third consecutive cycle [41].

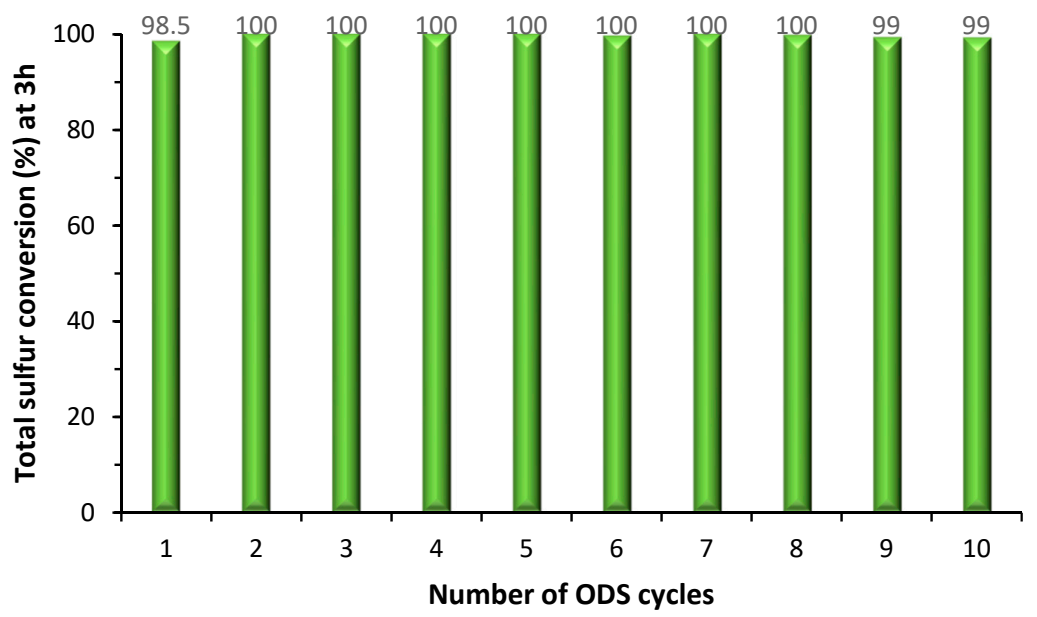

Figure 3. Desulfurization results of a multicomponent model diesel after $3 \mathrm{~h}$ for ten consecutive cycles, using a solvent-free system with $\mathrm{H}_{2} \mathrm{O}_{2} / \mathrm{S}=3$ and catalyzed by TBA[PW 11 . 


\subsection{Catalysts Stability}

The robustness of the TBA[PW 11 hybrid was investigated by recovering the catalyst after catalytic use (ac) and analyzing the solid by FTIR-ATR and ${ }^{31} \mathrm{P}$ NMR spectroscopies. The FTIR spectrum of TBA[PW 11$]$-ac (Figure 4) still exhibits the characteristic vibrational bands of the starting hybrid. The FT-IR spectrum of TBA[PW $\left.\mathrm{PW}_{11}\right]$ exhibits the bands associated with the $v_{\text {as }}(\mathrm{P}-\mathrm{O}), v_{\mathrm{as}}\left(\mathrm{W}-\mathrm{O}_{\mathrm{t}}\right)$, $v_{\mathrm{as}}\left(\mathrm{W}-\mathrm{O}_{\mathrm{b}}-\mathrm{W}\right)$ and $v_{\mathrm{as}}\left(\mathrm{W}-\mathrm{O}_{\mathrm{c}}-\mathrm{W}\right)$ vibrational modes of POM at 1081-1049, 957-952, 892-890 and $814-802 \mathrm{~cm}^{-1}$, respectively. The spectrum also displays the characteristic bands associated with the cation, namely the $v_{\mathrm{as}}(\mathrm{C}-\mathrm{H})$ and $v_{\mathrm{s}}(\mathrm{C}-\mathrm{H})$ stretches located at 2961,2936 and $2873 \mathrm{~cm}^{-1}$, respectively. In fact, the bands associated with the inorganic POM framework and the organic cations can be observed without major shifts, suggesting that the main structure is preserved [30,41,50]. However, when compared with the spectra of the starting catalyst, the spectrum also shows some additional bands $\left(1280,1153,711,698,656\right.$ and $\left.615 \mathrm{~cm}^{-1}\right)$ that are related to the presence of adsorbed sulfur compounds that remain attached to the catalyst, as previously reported by our group [22,23,41].

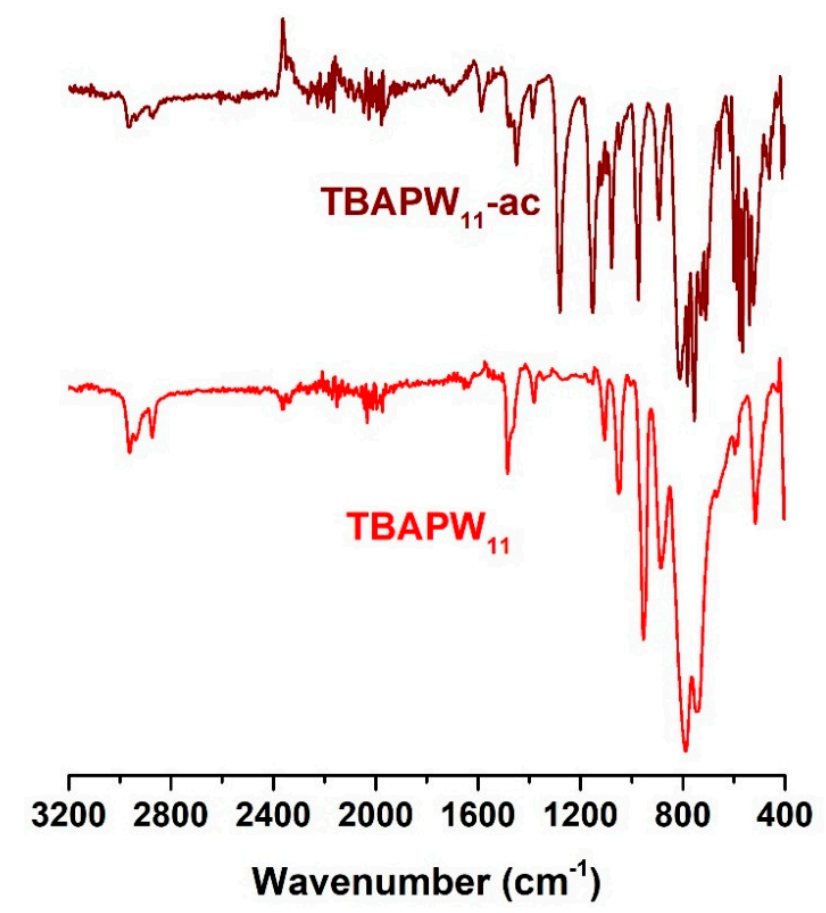

Figure 4. FT-IR spectra of $\mathrm{TBAPW}_{11}$ before and after catalytic use (ac).

The recovered solid after catalytic use, TBA[PW 11$]$-ac, was also characterized by ${ }^{31} \mathrm{P}$ NMR (Figure 5). The spectrum displays a main peak located at $\delta=-13.86 \mathrm{ppm}$ and another peak at $\delta=0.86 \mathrm{ppm}$. The first peak is shifted when compared with the signal of the starting TBA[PW $\left.{ }_{11}\right]$ $(-11.57 \mathrm{ppm})$ [41] and although the value is close to the ${ }^{31} \mathrm{P}$ NMR signal for the plenary Keggin anion $\left(\left[\mathrm{PW}_{12} \mathrm{O}_{40}\right]^{3-} \mathrm{PW}_{12}\right)$ which is $-13.38 \mathrm{ppm}$, previous catalytic studies showed the absence of catalytic activity from $\mathrm{PW}_{12}$ under these same experimental conditions. Nevertheless, it is well documented in the literature that the catalytic activity of the Keggin $\left(\mathrm{PW}_{12}\right)$ anion arises from its decomposition into active peroxotungstate species formed in the presence of excess $\mathrm{H}_{2} \mathrm{O}_{2}$ in biphasic systems [41,51]. In this work, the desulfurization results using TBA[PW $\mathrm{PW}_{11}$ show that the catalyst is able to oxidize the sulfur compounds and additionally without noticeable loss of activity along the reusability experiments. For all of the above, and despite the similar chemical shifts, we believe that the signal in the TBA[PW 11$]$-ac spectrum should also correspond to the $\mathrm{PW}_{11}$ structure with the lacunary region occupied by peroxo groups $\left(\mathrm{PW}_{\mathrm{x}} \mathrm{O}_{\mathrm{y}}\right.$ species). These peroxo-containing species are considered 
intermediates in the formation of the catalytic active peroxo-compounds, such as the species whose peak appears at $\delta=0.86 \mathrm{ppm}$ in the ${ }^{31} \mathrm{P}$ NMR spectrum [52].

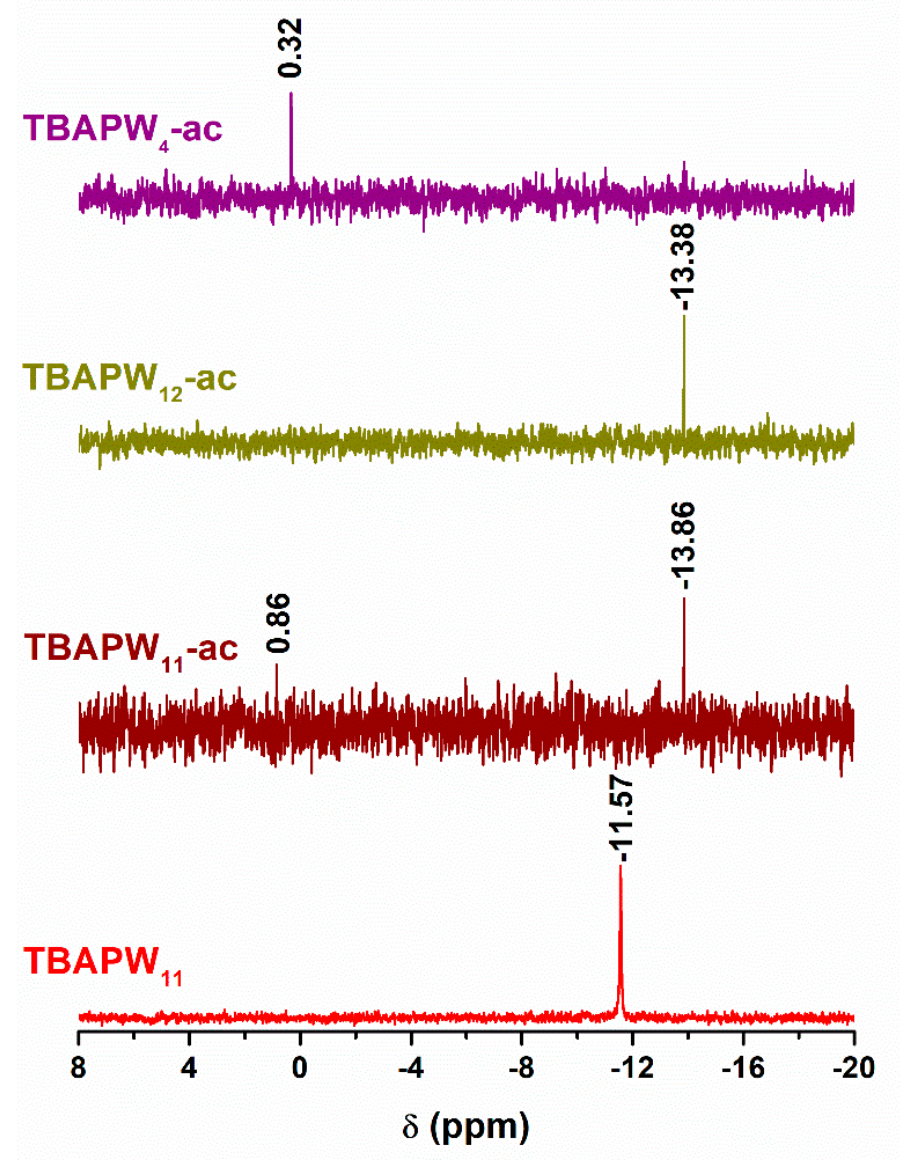

Figure 5. ${ }^{31} \mathrm{P}$ NMR spectra of as-synthetized TBA[PW 11$]$ and TBA[PW 11$], \mathrm{TBA}\left[\mathrm{PW}_{12}\right]$ and TBA[PW 4 after catalytic use (ac).

\section{Experimental}

\subsection{Materials and Methods}

All the reagents used for desulfurization experiments, including 1-benzothiophene (1-BT, Fluka, Buchs, Switzerland), dibenzothiophene (DBT, Aldrich, St. Louis, MO, USA), 4-methyldibenzothiophene (4-MDBT, Aldrich), 4,6-dimethyldibenzothiophene (4,6-DMDBT, Alfa Aesar, Haverhill, MA, USA), $n$-octane (Aldrich), hydrogen peroxide 30\% (Aldrich) were purchased from chemical suppliers and used without further purification.

Infrared absorption spectra were recorded for $400-4000 \mathrm{~cm}^{-1}$ regions on a Jasco 460 Plus spectrometer (Jasco Analytical Instruments, Easton, PA, USA), using $\mathrm{KBr}$ pellets. ${ }^{31} \mathrm{P}$ spectra were collected for liquid solutions using a Bruker Avance III 400 spectrometer (Bruker, Freemont, CA, USA) at $161.9 \mathrm{MHz}$ and $298 \mathrm{~K}$. The chemical shifts are given with respect to external $85 \%$ $\mathrm{H}_{3} \mathrm{PO}_{4}$. The catalytic reactions were monitored by a Bruker 430-GC-FID gas chromatograph (Bruker, Freemont, CA, USA), using a Supelco capillary column SPB-5 (30 m $\times 250 \mu \mathrm{m}$ id.; $25 \mu \mathrm{m}$ film thickness) and hydrogen as a carried gas $\left(55 \mathrm{~cm}^{3} \mathrm{~s}^{-1}\right)$, using the detector at $290{ }^{\circ} \mathrm{C}$ and the injector at $250{ }^{\circ} \mathrm{C}$ with an increasing oven temperature from 60 to $270{ }^{\circ} \mathrm{C}$, varying the heating rate between 5 and $20^{\circ} \mathrm{C} \mathrm{min}^{-1}$. 


\subsection{Synthesis and Characterization of POMs}

The syntheses of the potassium, tetrabutylammonium $\left(\mathrm{C}_{16} \mathrm{H}_{36} \mathrm{~N}\right.$, abbreviated as TBA) and trimethyloctadecylammonium $\left(\mathrm{C}_{21} \mathrm{H}_{46} \mathrm{~N}\right.$, abbreviated as ODA) salts of the lacunary polyoxometalate $\left[\mathrm{PW}_{11} \mathrm{O}_{39}\right]^{7-}: \quad \mathrm{TBA}_{4} \mathrm{H}_{3}\left[\mathrm{PW}_{11} \mathrm{O}_{39}\right] \quad\left(\mathrm{TBA}\left[\mathrm{PW}_{11}\right]\right)$ and $\mathrm{ODA}_{7}\left[\mathrm{PW}_{11} \mathrm{O}_{39}\right]\left(\mathrm{ODA}_{11}\left[\mathrm{PW}_{11}\right]\right.$ and $\mathrm{K}_{7}\left[\mathrm{PW}_{11} \mathrm{O}_{39}\right] \cdot 3 \mathrm{H}_{2} \mathrm{O}\left(\mathrm{K}\left[\mathrm{PW}_{11}\right]\right)$, respectively, were all previously reported by our research group [41].

\subsection{Desulfurization of Model Diesel}

A model diesel containing the most refractory sulfur compounds in real diesel (500 ppm or $0.0156 \mathrm{~mol} \mathrm{dm}^{-3}$ of sulfur from 1-BT, DBT, 4-MDBT and 4,6-DMDBT in $n$-octane) was used to investigate the oxidative desulfurization efficiency of TBA[PW 11$], \mathrm{ODA}\left[\mathrm{PW}_{11}\right]$ and $\mathrm{K}\left[\mathrm{PW} \mathrm{P}_{11}\right]$ catalysts. All catalytic experiments were carried out under atmospheric pressure in a closed borosilicate $5 \mathrm{~mL}$ reaction vessel loaded with a magnetic stirring bar and immersed in a thermostated oil bath at $70{ }^{\circ} \mathrm{C}$. A solvent-free system was employed by using the model diesel $(1 \mathrm{~mL})$, the catalyst $(3 \mu \mathrm{mol})$ and aqueous $\mathrm{H}_{2} \mathrm{O}_{2} 30 \%$ ( 0.24 or $0.61 \mathrm{mmol} ; \mathrm{H}_{2} \mathrm{O}_{2} / \mathrm{S}$ molar ratio $=3$ or 8 , respectively). Centrifugation was carried out after oxidation to separate the solid catalyst from model diesel. A liquid-liquid extraction using 1:1 ethanol/water ratio was performed when complete oxidation was achieved to remove the oxidized sulfur compounds from the model diesel. The sulfur content in the model diesel was periodically quantified by GC analysis using tetradecane as standard. For the reusability studies, the model diesel was easily removed from the reactor and the catalyst was dried in a desiccator overnight.

\section{Conclusions}

In this work, monovacant polyoxotungstate organic hybrids, TBA[PW $\left.\mathrm{PW}_{11}\right]$ and ODA[PW 11$]$, were evaluated as catalysts in a solvent-free desulfurization system. The ODA[PW 11$]$-based system showed a better performance by reaching a complete sulfur conversion of a multicomponent model diesel (2000 ppm S) after $40 \mathrm{~min}$, although a higher $\mathrm{H}_{2} \mathrm{O}_{2} / \mathrm{S}$ ratio was needed. In fact, the ODS results revealed that the catalytic activity of the hybrid catalysts is influenced by the type of cation and that long carbon chains favor the desulfurization process using an excess of $\mathrm{H}_{2} \mathrm{O}_{2}$ oxidant. The TBA[PW 11$]$-catalyzed system represents a more cost-effective desulfurization option since it was able to remove $96.5 \%$ of sulfur compounds in 120 min using a $\mathrm{H}_{2} \mathrm{O}_{2} / \mathrm{S}$ ratio of only 3 . Moreover, this system also showed a remarkable reusability and stability by producing clean diesel after $3 \mathrm{~h}$ of reaction for ten consecutive cycles without loss of activity. The proposed mechanism involves the formation of active peroxo-compounds through the interaction of the catalyst with the oxidant $\left(\mathrm{H}_{2} \mathrm{O}_{2}\right)$. The sustainability and cost-efficiency associated with the proposed solvent-free desulfurization system by avoiding the use of toxic organic solvents and using a reduced amount of oxidant makes it a very promising candidate for application in real diesel.

Supplementary Materials: The following are available online, Figure S1: ${ }^{31} \mathrm{P}$ NMR spectra of the TBA[PW 4 , TBA $\left[\mathrm{PW}_{11}\right]$ and $\mathrm{K}\left[\mathrm{PW}_{11}\right]$ in $\mathrm{CD}_{3} \mathrm{CN}$, Figure S2: FTIR-ATR spectrum of TBA[PW $]$.

Author Contributions: F.M. (supervised by B.d.C. and S.S.B.) performed all the experimental work related with the preparation of the materials and the oxidative desulfurization reactions. C.M.G. contributed with the discussion of the characterization data and manuscript preparation. All authors have read and agreed to the published version of the manuscript.

Funding: This work was partly funded through the projects REQUIMTE-LAQV [FCT (Fundação para a Ciência e a Tecnologia) Ref. LAQV, REQUIMTE (POCI-01-0145-FEDER-007265, UID/QUI/50006/2013)] and the project GlyGold PTDC/CTM-CTM/31983/2017, financed by national funds through the FCT/MEC and when appropriate co-financed by the Fundo Europeu de Desenvolvimento Regional (FEDER) under the PT2020 Partnership Agreement. This work is funded by national funds (OE), through FCT-Fundação para a Ciência e a Tecnologia, I.P., in the scope of the framework contract foreseen in the numbers 4, 5 and 6 of the article 23, of the Decree-Law 57/2016, of August 29, changed by Law 57/2017, of July 19.

Conflicts of Interest: The authors declare no conflict of interest. 


\section{References}

1. Lü, H.; Zhang, Y.; Jiang, Z.; Li, C. Aerobic oxidative desulfurization of benzothiophene, dibenzothiophene and 4,6-dimethyldibenzothiophene using an Anderson-type catalyst $\left[\left(\mathrm{C}_{18} \mathrm{H}_{37}\right)_{2} \mathrm{~N}\left(\mathrm{CH}_{3}\right)_{2}\right]_{5}\left[\mathrm{IMo}_{6} \mathrm{O}_{24}\right]$. Green Chem. 2010, 12, 1954-1958. [CrossRef]

2. Jiang, W.; Zhu, W.; Li, H.; Wang, X.; Yin, S.; Chang, Y.; Li, H. Temperature-responsive ionic liquid extraction and separation of the aromatic sulfur compounds. Fuel 2015, 140, 590-596. [CrossRef]

3. Xun, S.; Zhu, W.; Chang, Y.; Li, H.; Zhang, M.; Jiang, W.; Zheng, D.; Qin, Y.; Li, H. Synthesis of supported $\mathrm{SiW}_{12} \mathrm{O}_{40}$-based ionic liquid catalyst induced solvent-free oxidative deep-desulfurization of fuels. Chem. Eng. J. 2016, 288, 608-617. [CrossRef]

4. Soleimani, M.; Bassi, A.; Margaritis, A. Biodesulfurization of refractory organic sulfur compounds in fossil fuels. Biotechnol. Adv. 2007, 25, 570-596. [CrossRef] [PubMed]

5. Cychosz, K.A.; Wong-Foy, A.G.; Matzger, A.J. Liquid phase adsorption by microporous coordination polymers: Removal of organosulfur compounds. J. Am. Chem. Soc. 2008, 130, 6938-6939. [CrossRef] [PubMed]

6. Julião, D.; Ribeiro, S.; de Castro, B.; Cunha-Silva, L.; Balula, S.S. Polyoxometalates-based nanocatalysts for production of sulfur-free diesel. In Applying Nanotechnology to the Desulfurization Process in Petroleum Engineering; Tawfik, A.S., Ed.; IGI Global: Hershey, PA, USA, 2016; pp. 426-458.

7. Lü, H.; Li, P.; Deng, C.; Ren, W.; Wang, S.; Liu, P.; Zhang, H. Deep catalytic oxidative desulfurization (ODS) of dibenzothiophene (DBT) with oxalate-based deep eutectic solvents (DESs). Chem. Commun. 2015, 51, 10703-10706. [CrossRef] [PubMed]

8. Campos-Martin, J.M.; Capel-Sanchez, M.C.; Perez-Presas, P.; Fierro, J.L.G. Oxidative processes of desulfurization of liquid fuels. J. Chem. Technol. Biotechnol. 2010, 85, 879-890. [CrossRef]

9. Billeci, F.; D'Anna, F.; Gunaratne, H.Q.N.; Plechkova, N.V.; Seddon, K.R. "Sweet" ionic liquid gels: Materials for sweetening of fuels. Green Chem. 2018, 20, 4260-4276. [CrossRef]

10. Zhang, M.; Liu, J.; Li, H.; Wei, Y.; Fu, Y.; Liao, W.; Zhu, L.; Chen, G.; Zhu, W.; Li, H. Tuning the electrophilicity of vanadium-substituted polyoxometalate based ionic liquids for high-efficiency aerobic oxidative desulfurization. Appl. Catal. B 2020, 271, 118936. [CrossRef]

11. Julião, D.; Gomes, A.C.; Pillinger, M.; Lopes, A.D.; Valença, R.; Ribeiro, J.C.; Gonçalves, I.S.; Balula, S.S. Desulfurization of diesel by extraction coupled with Mo-catalyzed sulfoxidation in polyethylene glycol-based deep eutectic solvents. J. Mol. Liq. 2020, 309, 113093. [CrossRef]

12. Guerin, B.; Fernandes, D.M.; Daran, J.-C.; Agustin, D.; Poli, R. Investigation of induction times, activity, selectivity, interface and mass transport in solvent-free epoxidation by $\mathrm{H}_{2} \mathrm{O}_{2}$ and TBHP: A study with organic salts of the $\left[\mathrm{PMo}_{12} \mathrm{O}_{40}\right]^{3-}$ anion. New J. Chem. 2013, 37, 3466-3475. [CrossRef]

13. Jia, Y.; Li, G.; Ning, G. Efficient oxidative desulfurization (ODS) of model fuel with $\mathrm{H}_{2} \mathrm{O}_{2}$ catalyzed by $\mathrm{MoO}_{3} / \gamma-\mathrm{Al}_{2} \mathrm{O}_{3}$ under mild and solvent free conditions. Fuel Process. Technol. 2011, 92, 106-111. [CrossRef]

14. Malinenko, A.; Jonchere, A.; Girard, L.; Parrès-Maynadié, S.; Diat, O.; Bauduin, P. Are Keggin's POMs charged nano-colloids or multicharged anions? Langmuir 2018, 34, 2026-2038. [CrossRef] [PubMed]

15. Wang, S.-S.; Yang, G.-Y. Recent advances in polyoxometalate-catalyzed reactions. Chem. Rev. 2015, 115, 4893-4962. [CrossRef] [PubMed]

16. Ribeiro, S.; Granadeiro, C.M.; Silva, P.; Almeida Paz, F.A.; de Biani, F.F.; Cunha-Silva, L.; Balula, S.S. An efficient oxidative desulfurization process using terbium-polyoxometalate@MIL-101(Cr). Catal. Sci. Technol. 2013, 3, 2404-2414. [CrossRef]

17. Ribeiro, S.; Barbosa, A.D.S.; Gomes, A.C.; Pillinger, M.; Gonçalves, I.S.; Cunha-Silva, L.; Balula, S.S. Catalytic oxidative desulfurization systems based on Keggin phosphotungstate and metal-organic framework MIL-101. Fuel Process. Technol. 2013, 116, 350-357. [CrossRef]

18. Granadeiro, C.M.; Barbosa, A.D.S.; Ribeiro, S.; Santos, I.C.M.S.; de Castro, B.; Cunha-Silva, L.; Balula, S.S. Oxidative catalytic versatility of a trivacant polyoxotungstate incorporated into MIL-101(Cr). Catal. Sci. Technol. 2014, 4, 1416-1425. [CrossRef]

19. Nogueira, L.S.; Ribeiro, S.; Granadeiro, C.M.; Pereira, E.; Feio, G.; Cunha-Silva, L.; Balula, S.S. Novel polyoxometalate silica nano-sized spheres: Efficient catalysts for olefin oxidation and the deep desulfurization process. Dalton Trans. 2014, 43, 9518-9528. [CrossRef] 
20. Julião, D.; Gomes, A.C.; Pillinger, M.; Cunha-Silva, L.; de Castro, B.; Gonçalves, I.S.; Balula, S.S. Desulfurization of model diesel by extraction/oxidation using a zinc-substituted polyoxometalate as catalyst under homogeneous and heterogeneous (MIL-101(Cr) encapsulated) conditions. Fuel Process. Technol. 2015, 131, 78-86. [CrossRef]

21. Granadeiro, C.M.; Nogueira, L.S.; Juliao, D.; Mirante, F.; Ananias, D.; Balula, S.S.; Cunha-Silva, L. Influence of a porous MOF support on the catalytic performance of Eu-polyoxometalate based materials: Desulfurization of a model diesel. Catal. Sci. Technol. 2016, 6, 1515-1522. [CrossRef]

22. Mirante, F.; Ribeiro, S.O.; de Castro, B.; Granadeiro, C.M.; Balula, S.S. Sustainable desulfurization processes catalyzed by Titanium-polyoxometalate@TM-SBA-15. Top. Catal. 2017, 60, 1140-1150. [CrossRef]

23. Ribeiro, S.O.; Nogueira, L.S.; Gago, S.; Almeida, P.L.; Corvo, M.C.; Castro, B.D.; Granadeiro, C.M.; Balula, S.S. Desulfurization process conciliating heterogeneous oxidation and liquid extraction: Organic solvent or centrifugation/water? Appl. Catal. A 2017, 542, 359-367. [CrossRef]

24. Ribeiro, S.O.; Granadeiro, C.M.; Almeida, P.L.; Pires, J.; Capel-Sanchez, M.C.; Campos-Martin, J.M.; Gago, S.; de Castro, B.; Balula, S.S. Oxidative desulfurization strategies using Keggin-type polyoxometalate catalysts: Biphasic versus solvent-free systems. Catal. Today 2019, 333, 226-236. [CrossRef]

25. Ribeiro, S.O.; Granadeiro, C.M.; Almeida, P.L.; Pires, J.; Valença, R.; Campos-Martin, J.M.; Ribeiro, J.C.; de Castro, B.; Balula, S.S. Effective zinc-substituted Keggin composite to catalyze the removal of sulfur from real diesels under a solvent-free system. Ind. Eng. Chem. Res. 2019, 58, 18540-18549. [CrossRef]

26. Jiang, W.; Zheng, D.; Xun, S.; Qin, Y.; Lu, Q.; Zhu, W.; Li, H. Polyoxometalate-based ionic liquid supported on graphite carbon induced solvent-free ultra-deep oxidative desulfurization of model fuels. Fuel 2017, 190, 1-9. [CrossRef]

27. Leng, Y.; Wang, J.; Jiang, P. Amino-containing cross-linked ionic copolymer-anchored heteropoly acid for solvent-free oxidation of benzyl alcohol with $\mathrm{H}_{2} \mathrm{O}_{2}$. Catal. Commun. 2012, 27, 101-104. [CrossRef]

28. Lü, H.; Ren, W.; Liu, P.; Qi, S.; Wang, W.; Feng, Y.; Sun, F.; Wang, Y. One-step aerobic oxidation of cyclohexane to adipic acid using an Anderson-type catalyst $\left[\left(\mathrm{C}_{18} \mathrm{H}_{37}\right)_{2} \mathrm{~N}\left(\mathrm{CH}_{3}\right)_{2}\right]_{6} \mathrm{Mo}_{7} \mathrm{O}_{24}$. Appl. Catal. A 2012, 441-442, 136-141. [CrossRef]

29. Lü, H.; Gao, J.; Jiang, Z.; Yang, Y.; Song, B.; Li, C. Oxidative desulfurization of dibenzothiophene with molecular oxygen using emulsion catalysis. Chem. Commun. 2007, 150-152. [CrossRef]

30. Ribeiro, S.O.; Julião, D.; Cunha-Silva, L.; Domingues, V.F.; Valença, R.; Ribeiro, J.C.; de Castro, B.; Balula, S.S. Catalytic oxidative/extractive desulfurization of model and untreated diesel using hybrid based zinc-substituted polyoxometalates. Fuel 2016, 166, 268-275. [CrossRef]

31. Xue, X.; Zhao, W.; Ma, B.; Ding, Y. Efficient oxidation of sulfides catalyzed by a temperature-responsive phase transfer catalyst $\left[\left(\mathrm{C}_{18} \mathrm{H}_{37}\right)_{2}\left(\mathrm{CH}_{3}\right)_{2} \mathrm{~N}\right]_{7}$ PW11O39 with hydrogen peroxide. Catal. Commun. 2012, 29, 73-76. [CrossRef]

32. Zhang, Y.; Lü, H.; Wang, L.; Zhang, Y.; Liu, P.; Han, H.; Jiang, Z.; Li, C. The oxidation of benzothiophene using the Keggin-type lacunary polytungstophosphate as catalysts in emulsion. J. Mol. Catal. A Chem. 2010, 332, 59-64. [CrossRef]

33. Lü, H.; Deng, C.; Ren, W.; Yang, X. Oxidative desulfurization of model diesel using $\left[\left(\mathrm{C}_{4} \mathrm{H}_{9}\right)_{4} \mathrm{~N}_{6} \mathrm{Mo}_{7} \mathrm{O}_{24}\right.$ as a catalyst in ionic liquids. Fuel Process. Technol. 2014, 119, 87-91. [CrossRef]

34. Qiu, J.; Wang, G.; Zeng, D.; Tang, Y.; Wang, M.; Li, Y. Oxidative desulfurization of diesel fuel using amphiphilic quaternary ammonium phosphomolybdate catalysts. Fuel Process. Technol. 2009, 90, 1538-1542. [CrossRef]

35. Lü, H.; Gao, J.; Jiang, Z.; Jing, F.; Yang, Y.; Wang, G.; Li, C. Ultra-deep desulfurization of diesel by selective oxidation with $\left[\mathrm{C}_{18} \mathrm{H}_{37} \mathrm{~N}\left(\mathrm{CH}_{3}\right)_{3}\right]_{4}\left[\mathrm{H}_{2} \mathrm{NaPW}_{10} \mathrm{O}_{36}\right]$ catalyst assembled in emulsion droplets. J. Catal. 2006, 239, 369-375. [CrossRef]

36. Jiang, C.; Wang, J.; Wang, S.; Guan, H.Y.; Wang, X.; Huo, M. Oxidative desulfurization of dibenzothiophene with dioxygen and reverse micellar peroxotitanium under mild conditions. Appl. Catal. B 2011, 106, 343-349. [CrossRef]

37. Granadeiro, C.M.; de Castro, B.; Balula, S.S.; Cunha-Silva, L. Lanthanopolyoxometalates: From the structure of polyanions to the design of functional materials. Polyhedron 2013, 52, 10-24. [CrossRef]

38. Banisharif, F.; Dehghani, M.R.; Capel-Sánchez, M.; Campos-Martin, J.M. Desulfurization of fuel by extraction and catalytic oxidation using a vanadium substituted Dawson-type emulsion catalyst. Ind. Eng. Chem. Res. 2017, 56, 3839-3852. [CrossRef] 
39. Zhang, J.; Wang, A.; Li, X.; Ma, X. Oxidative desulfurization of dibenzothiophene and diesel over [Bmim $]_{3} \mathrm{PMo}_{12} \mathrm{O}_{40}$. J. Catal. 2011, 279, 269-275. [CrossRef]

40. Xu, Y.; Ma, W.-W.; Dolo, A.; Zhang, H. An amphiphilic catalyst based on sandwich-type polyoxometalate for deep desulfurization of fuels in ionic liquid. RSC Adv. 2016, 6, 66841-66846. [CrossRef]

41. Mirante, F.; Dias, L.; Silva, M.; Ribeiro, S.O.; Corvo, M.C.; de Castro, B.; Granadeiro, C.M.; Balula, S.S. Efficient heterogeneous polyoxometalate-hybrid catalysts for the oxidative desulfurization of fuels. Catal. Commun. 2018, 104, 1-8. [CrossRef]

42. Granadeiro, C.M.; Ferreira, P.M.C.; Julião, D.; Ribeiro, L.A.; Valença, R.; Ribeiro, J.C.; Gonçalves, I.S.; De Castro, B.; Pillinger, M.; Cunha-Silva, L.; et al. Efficient oxidative desulfurization processes using polyoxomolybdate based catalysts. Energies 2018, 11, 1696. [CrossRef]

43. Ribeiro, S.O.; Duarte, B.; De Castro, B.; Granadeiro, C.M.; Balula, S.S. Improving the catalytic performance of Keggin $\left[\mathrm{PW}_{12} \mathrm{O}_{40}\right]^{3-}$ for oxidative desulfurization: Ionic liquids versus SBA-15 composite. Materials 2018, 11, 1196. [CrossRef] [PubMed]

44. Jiang, X.; Li, H.; Zhu, W.; He, L.; Shu, H.; Lu, J. Deep desulfurization of fuels catalyzed by surfactant-type decatungstates using $\mathrm{H}_{2} \mathrm{O}_{2}$ as oxidant. Fuel 2009, 88, 431-436. [CrossRef]

45. Julião, D.; Mirante, F.; Ribeiro, S.O.; Gomes, A.C.; Valença, R.; Ribeiro, J.C.; Pillinger, M.; de Castro, B.; Gonçalves, I.S.; Balula, S.S. Deep oxidative desulfurization of diesel fuels using homogeneous and SBA-15-supported peroxophosphotungstate catalysts. Fuel 2019, 241, 616-624. [CrossRef]

46. Xie, D.; He, Q.; Su, Y.; Wang, T.; Xu, R.; Hu, B. Oxidative desulfurization of dibenzothiophene catalyzed by peroxotungstate on functionalized MCM-41 materials using hydrogen peroxide as oxidant. Chin. J. Catal. 2015, 36, 1205-1213. [CrossRef]

47. Zheng, H.; Sun, Z.; Chen, X.; Zhao, Q.; Wang, X.; Jiang, Z. A micro reaction-controlled phase-transfer catalyst for oxidative desulfurization based on polyoxometalate modified silica. Appl. Catal. A 2013, 467, 26-32. [CrossRef]

48. Zhu, W.; Zhu, G.; Li, H.; Chao, Y.; Zhang, M.; Du, D.; Wang, Q.; Zhao, Z. Catalytic kinetics of oxidative desulfurization with surfactant-type polyoxometalate-based ionic liquids. Fuel Process. Technol. 2013, 106, 70-76. [CrossRef]

49. Hill, C.L.; Kholdeeva, O.A. Selective liquid phase oxidations in the presence of supported polyoxometalates. In Liquid Phase Oxidation via Heterogeneous Catalysis; Clerici, M.G., Kholdeeva, O.A., Eds.; John Wiley \& Son: Hoboken, NJ, USA, 2013; pp. 263-319.

50. Granadeiro, C.M.; Barbosa, A.D.S.; Silva, P.; Paz, F.A.A.; Saini, V.K.; Pires, J.; de Castro, B.; Balula, S.S.; Cunha-Silva, L. Monovacant polyoxometalates incorporated into MIL-101(Cr): Novel heterogeneous catalysts for liquid phase oxidation. Appl. Catal. A 2013, 453, 316-326. [CrossRef]

51. Wang, S.-S.; Liu, W.; Wan, Q.-X.; Liu, Y. Homogeneous epoxidation of lipophilic alkenes by aqueous hydrogen peroxide: Catalysis of a Keggin-type phosphotungstate-functionalized ionic liquid in amphipathic ionic liquid solution. Green Chem. 2009, 11, 1589-1594. [CrossRef]

52. Liu, L.; Chen, C.; Hu, X.; Mohamood, T.; Ma, W.; Lin, J.; Zhao, J. A role of ionic liquid as an activator for efficient olefin epoxidation catalyzed by polyoxometalate. New J. Chem. 2008, 32, 283-289. [CrossRef]

Sample Availability: Samples of all the compounds are available from the authors.

Publisher's Note: MDPI stays neutral with regard to jurisdictional claims in published maps and institutional affiliations.

(C) 2020 by the authors. Licensee MDPI, Basel, Switzerland. This article is an open access article distributed under the terms and conditions of the Creative Commons Attribution (CC BY) license (http://creativecommons.org/licenses/by/4.0/). 